\title{
The oil spill model OILTRANS and its application to the Celtic Sea
}

\author{
*Berry, A., Dabrowski, T., Lyons, K. \\ Marine Institute, Rinville, Oranmore, Co. Galway, Ireland \\ corresponding author: alan.berry@marine.ie (Tel: +353 91387 360, Fax: +353 91387 201)
}

\begin{abstract}
This paper describes details of an oil spill model, OILTRANS, developed by the authors. The model is an off-line particle-transport model coupled to the most up to date operational met-ocean model forecasts. Formulations for the dominant oil fate processes of spreading, advection, diffusion, evaporation, emulsification and dispersion have been encoded, providing the model with the ability to accurately predict the horizontal movement of surface oil slick, the vertical entrainment of oil into the water column and the mass balance of spilled oil. The application of the OILTRANS model to an accidental release during a ship-to-ship fuel transfer in the Celtic Sea in February 2009 is presented to validate the system. Comparisons with aerial observations of the oil slick at the time of the incident, and subsequent model simulations, indicate that the OILTRANS model is capable of accurately predicting the transport and fate of the oil slick.
\end{abstract}

\section{Keywords}

oil spill model, oil weathering, particle transport, Celtic Sea, Kuznetsov.

\section{Introduction}

Oil spills are an inevitable and undesirable consequence of producing and transporting petroleum and associated refined products. More than two thirds of all large (>700ton) oil spills in the past forty years have occurred whilst vessels have been underway in open or inland waters and although the incidence of large and medium (7-700 ton) oil spills from vessels has significantly reduced in the past forty years, the trade in seaborne oil transportation has increased steadily since the mid 1980s (ITOPF, 2011). Whilst there has only been a limited number of oil spills around the Irish coast in the past forty years, recent data showing 12-13 million tonnes of oil and petroleum products transiting through Irish ports per annum (IMDO, 2010; IMDO, 2011) indicates that the risk persists of a large oil spill incident occurring.

The three questions of most importance at the time of any oil spill incident are; where will it go, when will it get there, and what will it be like when it arrives? The first two questions are critical in relation to the response operations for combating the spill and the answers to those questions rely on having accurate models for the hydrodynamics and wind fields for the relevant water body (Al 
Rabeh et al., 2000). The third question, the weathered state of the oil, is important for potential

removal operations and depends on using reliable oil fate and weathering algorithms. The processes through which oil weathers often occur simultaneously with each other, and the rate and significance of the weathering processes on the ultimate fate of the oil are dependant on the type of oil spilled, the spill location and the weather conditions at the time of the spill (API, 1999). Mackay and McAuliffe (1988) postulated that if oil is well characterised and the environmental conditions of wind speed and direction, sea state, currents, salinity and temperature are known, it should be possible to calculate the rates of many of the dominant oil weathering processes and thus establish how oil changes with time. Unfortunately, the rates of the oil spill processes are understood with different levels of confidence, and can be described by mathematical models that are partially based and calibrated on empirical results from laboratory or small scale field tests (Sebastiao and Guedes Soares, 1995).

In spite of these limitations, a large number of oil spill models have been developed over the past forty years (Aamo et al., 1995; Al Rabeh et al., 1995; Al Rabeh et al., 2000; Ambjorn, 2007; Carracedo et al., 2006; Chao et al., 2003; CONCAWE, 1983; Daling et al., 1997; French-McKay, 2004; Guo and Wang, 2009; Howlett, 1998; Inan and Balas, 2010; Lehr et al., 2002; Mackay et al., 1980a; Pollani et al., 2001; Reed, 1989; Reed et al., 1995; Spaulding et al., 1992; Tkalich and Xiaobo, 2001; Wang and Shen, 2010) and the state of the art in oil spill modelling has been reviewed by various authors (ASCE, 1996; Reed et al., 1999; Spaulding, 1988 ).

Oil spill models can be classified with respect to their stages of evolution as: first, second and third generation models (Cekirge et al., 1995). First generation models are transport models with limited fate algorithms. Second generation models consist of limited two-dimensional hydrodynamics and fate algorithms. The third generation model, or the comprehensive oil spill model consists of a set of algorithms to simulate the fate and transport of oil in three dimensions, including the processes of advection, diffusion, surface spreading, vertical mechanical dispersion, evaporation, emulsification and stranding (Cekirge et al., 1995).

This paper describes the development of such a third generation oil spill model, OILTRANS, with the transport of particles modelled using a lagrangian approach. The OILTRANS model underpins the newly developed operational oil spill forecasting system at the authors' institute, which is detailed in a related paper. The OILTRANS model is applied to simulate an accidental release during a ship-to-ship fuel transfer in the Celtic Sea in February 2009 and is one of the first published oil spill modelling case studies in Irish waters. OILTRANS results are compared with aerial observations of the oil slick at the time of the incident, and subsequent model simulations of the fate processes. 


\section{Materials and methods}

\subsection{Modelling system components}

The OILTRANS model consists of two interlinked modelling components, a lagrangian particle transport module and an oil fates module. The OILTRANS model consumes output from two operational forecast models; one meteorological and one oceanographic, with the option to consume output from a wave forecast model subject to certain conditions. See Figure 1 for system schematic. Output from the meteorological forecast model provides free surface boundary conditions to the oceanographic forecast model, and provides surface wind fields to both the oil fates and particle transport modules. Output from the oceanographic forecast model provides three dimensional fields of water currents to the particle transport module and three dimensional fields of water density and temperature to the oil fates module. The interlinked particle transport and oil fates modules of the OILTRANS model exchange information with each other on the fate of the slick during runtime.

\subsubsection{Meteorological model}

The meteorological forecast model used by the authors to provide input to both the oceanographic forecast model and the OILTRANS model is the half-degree Global Forecasting System (GFS) provided by the National Oceanic and Atmospheric Administration (NOAA) (GCWMB, 2003). The meteorological model forecasts are spatially interpolated by the authors onto a common model domain shared by both the oceanographic and OILTRANS models.

\subsubsection{Oceanographic model}

The oceanographic forecast model which is used operationally by the authors to provide input to the OILTRANS model is the Regional Ocean Modelling System, (ROMS). ROMS is a free-surface, hydrostatic, primitive equation ocean model described in Shchepetkin and McWilliams (2005). ROMS uses orthogonal curvilinear coordinates on an Arakawa-C grid in the horizontal while utilizing a terrain-following (sigma) coordinate in the vertical. The model domain covers a significant portion of the Northwest European continental shelf at a variable horizontal resolution (between $1.2 \mathrm{~km}$ and $2.5 \mathrm{~km}$ ) and with 40 sigma levels. The model bathymetry utilizes data from a number of sources to produce the best possible bathymetry for the area. Atmospheric forcing at the sea surface at three-hourly intervals is interpolated from the GFS forecast model, while tide forcing is prescribed at the model boundaries by applying water surface elevations and barotropic velocities for ten major tide constituents which are obtained from OTIS, the Oregon State University Tidal Data Inversion Software (TPXO7.2) global inverse barotropic tide model (Egbert and Erofeeva, 2002). The model is nested within the high resolution (1/12) Mercator Ocean PSY2V4R2 
operational model of the North Atlantic whereby daily values for potential temperature, sea surface

height and velocity are linearly interpolated from the parent model onto our model grid at the boundaries. Bottom stress is applied using the logarithmic "law of the wall" with a roughness coefficient of $0.01 \mathrm{~m}$. Surface stress is calculated using the COARE algorithm (Fairall et al., 1996). The model simulates temperature, salinity, currents and sea surface height throughout the whole domain and is run operationally, producing a 3-day forecast every weekday and one 7-day hindcast every week, the output of which is archived for future use.

\subsubsection{Wave model}

The wave forecast model that may be used as an option to provide input to the OILTRANS model is the SWAN model. SWAN is a third-generation wave model and can be used on any scale relevant for wind-generated surface gravity waves (Delft, 2011). As SWAN facilitates a variety of grid structures and nesting options, a pre-condition of using the SWAN model to provide input to the OILTRANS model is that the SWAN output be re-configured to the model grid common to both the oceanographic and OILTRANS models.

\subsubsection{Particle transport model}

The OILTRANS particle transport model is based on the LTRANS v.2 particle transport model developed by North et al. (2011). LTRANS v.2 was initially developed to simulate oyster larvae, and was modified by the authors to simulate oil particles. LTRANS v.2 is an off-line particletransport model that runs with the stored predictions of a 3D hydrodynamic model, specifically ROMS. The archived predictions from both the ROMS hydrodynamic and GFS meteorological models are interpolated in space and time to the particle location. Two dimensional water and wind properties are interpolated to the particle location using bi-linear interpolation. Three dimensional water properties are interpolated to the particle location using a water column profile created by fitting a tension spline curve in the vertical to the interpolated values at each sigma level (North et al., 2006). LTRANS v.2 includes a 4th order Runge-Kutta scheme for particle advection and a random displacement model for vertical turbulent particle motion. OILTRANS expanded the LTRANS v.2 particle transport code to include for mechanical spreading of oil slick particles and the advection of oil particles due to wind drift.

\subsubsection{Oil fates model}

The oil fates module of OILTRANS was developed to simulate the processes governing the evolution and behaviour of oil spilled on the water surface. The oil fates, or weathering, processes occur at very different rates, but begin almost immediately after the oil is spilled. All weathering and transport processes are strongly dependant on the type of oil, the volume of oil spilled and the 
weather conditions during a spill event. After Fingas (2011), the order of importance of the

weathering processes encoded in the model are: evaporation, emulsification and natural dispersion. Implementation of the weathering process algorithms chosen for the OILTRANS model are detailed in subsequent sections.

\subsection{OILTRANS oil fate governing equations}

The processes encoded in OILTRANS to describe the physical and chemical weathering processes of spilled oil include: advection of the slick due to currents and wind drift, diffusion of the oil particles due to random motions, the mechanical spreading of the slick under gravity and viscous forces, the evaporation from the slick of the lighter components of the spilled oil, the entrainment of water into the oil slick forming emulsions, and the dispersion of the smaller droplets of oil into the water column through the action of breaking waves. These processes are considered by the authors to be the dominant mechanisms through which oil is removed from the marine environment. The processes of dissolution, biodegradation, sedimentation and photo-oxidation have not been encoded in the current version of OILTRANS as it is considered that they represent the removal of only a very small fraction of spilled oil during the first three days of a spill, the period of the operational oil spill forecast system. In a novel departure from other oil spill modelling systems, OILTRANS allows for user to select a number of different algorithms for the processes of mechanical spreading, evaporation and emulsification. Details of the algorithms for the current implementation of OILTRANS are presented below, with the alternate encoded formulations referenced briefly.

\subsubsection{Mechanical spreading}

Oil will spread on the surface of a water body even without external forces such as tidal currents or wind stresses. The spreading of the oil on calm waters is due to the force of gravity and the interfacial tension between oil and water, with the oil viscosity and inertia retarding the spreading forces (Fay, 1969). The most widely used formulations for determining the rate of spread of oil on the water's surface are the equations proposed by Fay (1971), or versions thereof. Fay divided spreading into three phases. The first phase known as the gravity-inertial phase generally lasts for less than an hour, except for the largest of spills and is not modelled by OILTRANS. As the time for the first gravity-inertial phase is so short, OILTRANS begins the oil weathering processes once the end time, $t_{0}$, of this first phase has been reached, which was determined by Fay (1971) to be: 
$t_{o}=\left(\frac{k_{2}}{k_{1}}\right)^{4}\left(\frac{V_{o}}{v_{w} g \Delta \rho}\right)^{1 / 3}$

where $k_{1} \& k_{2}$ are empirical coefficients (1.14 \& 1.45 respectively, after Fay (1971)), $V_{o}$ is the original volume of spilled oil $\left(\mathrm{m}^{3}\right), v_{w}$ is the kinematic viscosity of water $\left(\mathrm{m}^{2} / \mathrm{s}\right), g$ is gravitational acceleration $\left(\mathrm{m} / \mathrm{s}^{2}\right)$, and $\Delta \rho$ is the relative density difference between water and oil given by:

$\Delta \rho=\frac{\rho_{w}-\rho_{\text {oil }}}{\rho_{w}}$

where $\rho_{\mathrm{w}}$ is the density of water $\left(\mathrm{g} / \mathrm{cm}^{3}\right)$ and $\rho_{\text {oil }}$ is the density of oil $\left(\mathrm{g} / \mathrm{cm}^{3}\right)$. The area $\left(\mathrm{m}^{3}\right)$ over which the oil slick has spread at the end of this first spreading phase was determined by Fay (1971) to be:

$$
A_{o}=\pi \frac{k_{2}^{4}}{k_{1}^{2}}\left(\frac{V_{o}^{5} g \Delta \rho}{v_{w}^{2}}\right)
$$

The second stage of slick spreading known as the gravity-viscous phase is governed by the balance between the viscosity of the oil and the oil-water interfacial tension. The viscous spreading phase continues to such a time that the slick gets so thin that surface tension forces alone play a role in spreading the slick, leading to the third, surface-tension, phase. This third phase is not modelled in OILTRANS as it occurs at much later stages in slick spreading, rather a terminal oil film thickness is defined in OILTRANS to denote the end of the gravity viscous phase after which no further mechanical spreading occurs. Generally, by this time significant weathering will have occurred and the slick is allowed to disperse horizontally or break into smaller slicks due to surface current shears.

The general spreading formulae proposed by Fay (1971) only deal with an idealised spreading of a slick in a radial manner on calm seas. They take no account of wind conditions, which play an important role in determining the shape and area of actual spills. Results of field experiments on the spreading of oil slicks have been reported by Elliott et al. (1986), Jeffrey (1973) and Lehr et al. (1984), all of which found that slicks developed elongated shapes, with the major axis orientated in the direction of the wind. Lehr et al. (1984) devised a Fay-type formula to account for the elongation of the oil slick in the direction of the wind.

Using the assumptions adopted by previous researchers (Al Rabeh et al., 2000; Chao et al., 2003; Gou and Wang, 2009; Inan and Balas, 2010, Nagheeby and Kolahdoozan, 2008), that the slick is elliptical in shape with the major axis orientated in the direction of the wind, the area, $\mathrm{A}\left(\mathrm{x} 10^{3} \mathrm{~m}^{2}\right)$, of the oil slick once the gravity-viscous spreading phase has commenced, can be represented as: $A=1 / 4 \pi Q R$ where Q and R are the lengths of the minor and major ellipse axis respectively, given by : 


$$
Q=1.7\left(\Delta \rho V_{o}\right)^{1 / 3} t^{1 / 4}
$$

$R=Q+0.03 U_{\text {wind }}^{4 / 3} t^{3 / 4}$

where in this case, $V_{o}$ is the volume of the spill (bbl), $t$ is the time after the oil slick commences spreading (min) and $U_{\text {wind }}$ is the wind speed (kts). Following the method adopted by Al Rabeh et al. (1989, 1995, 2000), the slick can be conceptualised as a series of concentric ellipses in a local Cartesian reference frame $\mathrm{X}^{*} \mathrm{Y}^{*}$ with the centre of mass of the slick located at the local coordinates of $\left(x^{*}, y^{*}\right)=(0,0)$, see Figure 2 . The local $X^{*}$ axis of the slick is orientated in the direction of the wind. The elliptical spreading of the slick over time is assumed to be uniform, in that;

$\frac{r}{R}=\frac{r+\Delta r}{R+\Delta R}$

$\frac{q}{Q}=\frac{q+\Delta q}{Q+\Delta Q}$

$\frac{q}{Q}=\frac{r}{R}$

where $r$ and $q$ are the lengths of the major and minor axis of an interior ellipse, $\Delta r$ and $\Delta q$ are the increases in length of the major and minor axis of an interior ellipse in time-step $\Delta t(\mathrm{~min})$, and $\Delta R$ and $\Delta Q$ are the increases in length of the major axis and minor axes of the outer ellipse in time-step $t$ (min).

Any oil particle constituting the slick will therefore be subjected to a displacement proportional to the increase in the length of the respective axes with time. Given the location of a particle on an interior ellipse at coordinates, $x_{t}{ }_{t}, y_{t}{ }_{t}$, which can be rewritten as $x^{*}{ }_{t}=r \cos \theta$ and $y_{t}{ }_{t}=q \sin \theta$, the displacement of the particle outwards by $\Delta x^{*}$ and $\Delta y^{*}$ by spreading has been calculated by $\mathrm{Al}$ Rabeh et al. (2000) to be:

$$
\begin{aligned}
& \Delta x^{*}=\Delta r \cos \theta=\Delta r\left(x_{t}^{*} / r\right)=x_{t}^{*}(\Delta R / R) \\
& \Delta y^{*}=\Delta r \sin \theta=\Delta r\left(y_{t}^{*} / q\right)=y_{t}^{*}(\Delta Q / Q)
\end{aligned}
$$

where the values of $\Delta Q$ and $\Delta R$ are given by the formulae;

$$
\begin{aligned}
& \Delta Q=1.7\left(\Delta \rho V_{o}\right)^{1 / 3} 1 / 4^{-3 / 4} \cdot \Delta t \\
& \Delta R=\Delta Q+0.03 U_{\text {wind }}^{4 / 3} 3 / t^{-1 / 4} \cdot \Delta t
\end{aligned}
$$

with units as those in equation (5) and (6). As the local Cartesian reference frame for the slick is orientated in the direction of the wind, the coordinates must be converted to the global cartesian coordinate system used by the OILTRANS model by means of the following transformations; 
$x=(\cos \varphi) x^{*}+(\sin \varphi) y^{*}$

$y=(-\sin \varphi) x^{*}+(\cos \varphi) y^{*}$

where $\varphi$ is the angle between the wind direction and the positive $\mathrm{x}$-axis of the OILTRANS model domain. After each time-step in the OILTRANS model, the centre of mass of the oil slick is recalculated and becomes the origin of a new local coordinate system for a new set of concentric ellipses, the extent of which is calculated from equations (5) and (6).

The classical Fay (1971) formulation for mechanical spreading, in the absence of wind effects, is also encoded in the OILTRANS system for sensitivity analyses and to give end users the options to choose an alternative algorithm for local implementations.The calculation of the elliptical spreading of the oil slick is undertaken during the gravity-viscous phase of the spreading of the oil slick and only until the terminal oil slick thickness is reached. Once the terminal oil slick thickness is reached the spreading assumption is removed and the slick is allowed to spread under the influence of horizontal diffusion, surface winds and water current shears, as detailed below, to represent complex, realistic surface slicks.

\subsubsection{Advection and diffusion.}

The movement of an oil slick at the water surface can be considered as being composed of the advection of the oil slick by both surface currents $\left(U_{\text {current }}\right)$, wind effects $\left(U_{\text {wind }}\right)$, and the diffusion of oil particles as a result of random processes (ASCE 1996; Ambjorn 2007; Guo et al 2009; Carracedo 2006, Cheng, 2011, Jordi et al 2006). The advection of the oil slick due to surface currents is taken to be the current velocity as predicted in the surface layer of the water column by the authors' oceanographic model, $U_{\text {current }}$.

There are a number of processes that are associated with wind effects and most oil spill models represent them with a simple wind drift factor (Guo \& Wang, 2009; French McKay, 2004; Nagheeby and Kolahdoozan, 2008, Perianez, 2010). Most oceanographic models do not adequately resolve the uppermost centimeter of the water column at the air-water interface and thus tend to underpredict the actual wind induced surface current. Allowance is made for this through incorporation into the wind drift factor, as in Ambjorn (2007). Based on sensitivity testing the cumulative wind drift factor was set at 3.5\% of the wind speed, which is in keeping with values found in published literature (Carracedo 2006; Guo \& Wang, 2009; French McKay, 2004; Perianez, 2010)rench-McKayBIn addition to the advective wind drift factor, a Coriolis force correction is also introduced, whereby the surface slick is deflected to the right by a drift angle, which is set to $5^{\circ}$. It follows therefore that the centre of mass of the oil slick is advected by surface currents and wind effects according to: 
$U_{a}=U_{\text {current }}+0.035 U_{\text {wind }}$

where $U_{a}$ is the advective velocity of the oil slick (m/s). By modelling the oil spill as a large number of discrete lagrangian particles in an XY planar reference frame at the water surface such that $\left(x_{t}, y_{t}\right)$ represents the location of a particle at time-step $t$, the location of that particle at time-step $t+1$ due to advective and diffusive transport processes will be $\left(x_{t+1}, y_{t+1}\right)$ where:

$x_{t+1}=x_{t}+u_{a}\left(x_{t}, y_{t}\right) \Delta t+\Delta x_{\text {diff }}$

$y_{t+1}=y_{t}+v_{a}\left(x_{t}, y_{t}\right) \Delta t+\Delta y_{\text {diff }}$

where $u_{a}\left(x_{t}, y_{t}\right)$ and $v_{a}\left(x_{t}, y_{t}\right)$ are the $\mathrm{u}$ and $\mathrm{v}$ components of the interpolated advective velocity $U_{a}$ at location $x, y$ in the $\mathrm{X}$ and $\mathrm{Y}$ directions respectively $(\mathrm{m} / \mathrm{s}), \Delta t$ is the time-step interval (s), $\Delta x_{\text {diff }}$ and $\Delta y_{\text {diff }}$ are the diffusive displacements of the particle in the $\mathrm{X}$ and $\mathrm{Y}$ directions respectively due to random process. Based on the work by $\mathrm{Al}$ Rabeh et al. (1989) the values of $\Delta x_{\text {diff }}$ and $\Delta y_{\text {diff }}$ can be calculated as:

$\Delta x_{\text {diff }}=[R]_{0}^{1} \sqrt{12 D_{h} \Delta t} \cos \theta$

$\Delta y_{\text {diff }}=[R]_{0}^{1} \sqrt{12 D_{h} \Delta t} \sin \theta$

where $[R]_{0}^{1}$ is a random number uniformly distributed between 0 and $1, D_{h}$ is the horizontal diffusion coefficient $\left(\mathrm{m}^{2} / \mathrm{s}\right)$ and is user-definable, and $\theta$ is the directional angle assumed to be uniformly distributed between 0 and $2 \pi$ (ie. $\theta=2 \pi[R]_{0}^{1}$ ).

\subsubsection{Evaporation}

Evaporation is the primary weathering process involved in the natural removal of oil from the sea surface, with the rate of evaporation being determined by the oil properties and increasing due to the spreading of the oil, seawater temperature and wind speed (CONCAWE, 1983). The evaporation process in OILTRANS is modelled using the pseudo-component approach adopted by Jones (1997) where the oil is approximated as an ideal mixture of a small number of components. Each component is characterised by a mole fraction and vapour pressure. The total evaporation rate for the oil is the sum of the evaporation rates of each component, $i$, which is expressed as:

$$
\frac{d V_{i}}{d t}=\frac{K_{i} A(t) P_{i} \bar{V}_{i} \chi(t)_{i}}{R T}
$$

Where $A$ is the area of the oil slick $\left(\mathrm{m}^{2}\right)$, at time $t, R$ is the gas constant, $\mathrm{T}$ is the oil temperature, assumed equal to the water temperature $\left({ }^{0} \mathrm{~K}\right), K_{i}$ is the mass transfer coefficient, expressed after Mackay and Matsugu (1973) as: 


$$
K_{i}=0.0048 U_{\text {wind }}^{7 / 9} X^{-1 / 9} S c^{-2 / 3}
$$

Where $X$ is the downwind length of the oil slick axis (m), Sc is the Schmidt number based on the mole weighted average of the oil $\left(M W_{\text {avg }}\right)$, and calculated after Lehr et al. (2002) to be:

$S_{c}=1.3676\left(\frac{0.018}{M W_{\text {avg }}}\right)^{-1 / 2}$

$\bar{V}_{i}$ is the molar volume of each component $i$, correlated by Jones (1997) to boiling point data to give:

$\bar{V}_{i}=7.0 \times 10^{-5}-\left(2.102 \times 10^{-7} B P_{i}\right)+\left(1.0 \times 10^{-9} B P_{i}^{2}\right)$

where $B P_{i}$ is the boiling point cut for each component, $i$. $P_{i}$, the vapour pressure of component $i$, is given by Antoine's equation as:

$\ln \frac{P_{i}}{P_{a}}=\frac{\Delta S_{i}\left(B P_{i}-C_{2}\right)^{2}}{R \cdot B P_{i}}\left[\frac{1}{B P_{i}-C_{2}}-\frac{1}{T-C_{2}}\right]$

where $P_{a}$ is atmospheric pressure $(\mathrm{Pa}), C_{2}$ is a coefficient $=0.19\left(B P_{i}-18.0\right), \Delta S_{i}$ is a coefficient $=$ $8.75+1.987 \log \left(B P_{i}\right), \chi(t)_{i}$ is the mole fraction of component, $i$, at time, $t$, which can be expressed in terms of volumes and molar volumes as:

$$
\chi(t)_{i}=\frac{V_{i} / \bar{V}_{i}}{\sum_{j=1}^{i_{\max }} V_{j} / \bar{V}_{j}}
$$

Substituting equations (19), (20) and (21) into equation (18) gives:

$$
\frac{d V_{i}}{d t}=\frac{0.0656 \cdot U_{\text {wind }}^{7 / 9} \cdot\left(0.018 / M W_{\text {avg }}\right)^{1 / 3}}{X^{1 / 9}} \cdot \frac{A(t) P_{i}}{R T} \cdot \frac{V_{i}}{\sum_{j=1}^{i_{\max }} V_{j} / \bar{V}_{j}}
$$

This equation is solved in each time step to determine $\frac{d V_{i}}{d t}$. The final term in equation (24), the volumetric mole fraction term, is recalculated at the end of each time-step to account for the losses from each component, $i$, in that time-step. The total fraction of oil evaporated, $F_{\text {evap }}$, is then the sum of the volumes of the components evaporated divided by the initial volume of the oil. The evaporation algorithms of both Stiver and Mackay (1984) and Fingas (1999) are also encoded in the OILTRANS system for use in sensitivity analyses and to give end users the options to choose an alternative algorithm for local implementations. Emulsification will affect the evaporation rate, therefore a factor of $(1-Y)$ is applied to account for the fraction of oil that is in emulsion, where $Y$ is the water content of the emulsified oil, (see section 2.2.4) 


\subsubsection{Emulsification}

Emulsification is the second most important weathering process after evaporation (Fingas and Fieldhouse, 2001). Emulsification is the process by which water droplets are incorporated into an oil slick. The most important characteristics of a water-in-oil emulsion is its stability (Fingas et al., 1999). The classification of stability is important before one can identify the properties of the emulsion, as they change significantly for each type of emulsion (Fingas and Fieldhouse, 2001). Extensive studies on over four hundred oil types have classified water-in-oil emulsions into four stability types; stable, mesostable, entrained and unstable. Emulsion formation in the OILTRANS model is modelled using the approach of Fingas and Fieldhouse (2004), subsequently improved by Fingas (2011) where the stability class is directly predicted from empirical data, herein referred to as the Fingas method. To the best of the authors knowledge, this is the first implementation of the Fingas method in an operational oil spill modelling system.

The first step in this method is to calculate the oil properties at the weathering condition of concern, which is accomplished internally in the OILTRANS model's evaporation, density, viscosity and dispersion subroutines. A review of knowledge on water in oil emulsions (Fingas and Fieldhouse 2006) found that the asphaltene and resin content are primarily responsible for stabilty whilst a previous study (Fingas and Fieldhouse 2003) determined that while the wax content showed some correlation to viscosity, it was not associated with the formation of any state of emulsion. The oil properties required for the Fingas method are thus the density, viscosity, and saturate, resin and asphaltene contents of the weathered oil. These values are then transformed in the manner of Fingas (2011) and substituted into the following equation to determine the stability class:

Stability $C=12.3+0.259 S t-1.601 R t-17.2(\mathrm{~A} / \mathrm{Rt})$

$$
\begin{aligned}
& -0.50 V t^{3}+0.002 R t^{3}+0.001 \mathrm{At}^{3}+8.51(\mathrm{~A} / \mathrm{R} t)^{3} \\
& -1.12 \log (\mathrm{Vt})+0.7 \log (R t)+2.97 \log (\mathrm{A} / \mathrm{R} t) \\
& +6.0 \times 10^{-8}(\exp (\mathrm{Vt}))^{2}-1.96(\exp (\mathrm{A} / \mathrm{R} t))^{2} \\
& -4.0 \times 10^{-6} \log _{10}(\mathrm{Dt}) /(\mathrm{Dt})^{2}-1.5 \times 10^{-4} \log _{10}(\mathrm{~A} / \mathrm{R} t) /(\mathrm{A} / \mathrm{R} t)^{2}
\end{aligned}
$$

where: Stability $C$ is the stability classification, $S t$ is the transformed saturate content (\%), $R t$ is the transformed resin content (\%), $A / R t$ is the transformed asphaltene/resin ratio, $V t$ is the transformed natural logarithm of viscosity (mPas), $A t$ is the transformed asphaltene content (\%), and $D t$ is the transformed exponential of the oil density $\left(\mathrm{g} / \mathrm{cm}^{3}\right)$. The calculated values of Stability $C$ are then related to the emulsion state, with associated conditions where applicable, according to (Fingas, 2011). In addition, the viscosity of the resulting emulsion has been determined as a multiplicative factor on the starting oil viscosity and can be taken as the average value for the emulsions types at a given time, following the values provided by Fingas (2011). The water content of the resulting emulsion type at given times has also been determined by Fingas (2011) and is included in the 
OILTRANS formulations. The time to formation of the emulsions has previously been studied by Fingas and Fieldhouse (2004), who related the time to formation of each emulsion type to the energy required for formation (expressed as equivalent wave height) and expressed as:

$y=a+\left(b / x^{1.5}\right)$

where $y$ is the time to formation ( $\mathrm{min}$ ), $a \& b$ are coefficients depending on emulsion type after Fingas (2011), and $x$ is the wave height (cm). The emulsification algorithms of Mackay et al. (1980a, 1980b) are also encoded in the OILTRANS system for use in sensitivity analyses and to give end users the options to choose an alternative algorithm for local implementations.

\subsubsection{Dispersion}

Natural dispersion, or entrainment, of oil slicks at sea occurs when droplets of oil are mixed into the water column by breaking waves. If the droplets are small enough natural turbulence in the water will prevent the oil from resurfacing whilst larger droplets tend to rise and will not stay in the water column for more than a few minutes. The droplets that stay in the water column are considered to be permanently dispersed. The natural dispersion process within the OILTRANS model is based on the classic method of Delvigne and Sweeney (1988) who developed a relationship for entrainment rate, $Q_{d}$, as a function of droplet size and oil viscosity, as:

$Q_{d}=C^{*} D_{d}^{0.57} S F d^{0.7} \Delta d$

where: $Q_{d}$ is the entrainment rate, $\left(\mathrm{kg} / \mathrm{m}^{2} \mathrm{~s}\right)$, for droplet diameter $d,(\mathrm{~m}), C^{*}$ is an empirical entrainment constant which depends on oil type and weathering state. Using a series of experimental data by Delvigne and Hulsen (1994), the entrainment constant, $C^{*}$, was fit to the following equations by French-McCay (2004):

$C^{*}=\exp \left(-0.1023 \ln \left(v_{\text {oil }}\right)+7.575\right) \quad$ for $v_{\text {oil }}<132(c S t)$

$C^{*}=\exp \left(-1.8927 \ln \left(v_{\text {oil }}\right)+16.313\right)$ for $\left.v_{\text {oil }}\right) \geq 132(c S t)$

where: $v_{\text {oil }}$ is the viscosity of the oil, (cSt). $D_{d}$ is the dissipated breaking wave energy per unit surface area, $\left(\mathrm{J} / \mathrm{m}^{2}\right)$, and is given by:

$D_{d}=0.0034 \rho_{w} g H_{b}^{2}$

where $H_{b}$ is the breaking wave height, assumed to be equal to $1.5 H_{\text {sig }}$ using the simple estimate of Liungman and Mattsson (2011) where $H_{\text {sig }}$ is the significant wave height (m), and assuming a fully developed sea-state, can be calculated according to CERC (1984) as;

$$
H_{\text {sig }}=\left(\frac{0.243 U_{*}^{2}}{g}\right)
$$

where $U_{*}^{2}=0.71 U_{\text {wind }}^{1.23}$, is the wind stress factor associated with the $10 \mathrm{~m}$ wind speed $U_{\text {wind }}(\mathrm{m} / \mathrm{s}) . S$ is the fraction of sea surface covered by oil (assumed as 0.75 ). $F$ is the fraction of sea surface hit by breaking waves and is parameterised as: 


$$
\begin{array}{ll}
F=3.0 \times 10^{-6}\left(U_{\text {wind }}^{3.5} / T_{w}\right) & \text { for } U_{\text {wind }}<U_{t h}, \\
F=3.2 \times 10^{-2}\left[\left(U_{\text {wind }}-U_{t h}\right) / T_{w}\right] & \text { for } U_{\text {wind }}>U_{t h},
\end{array}
$$

where $U_{t h}$ is the threshold $10 \mathrm{~m}$ wind speed for onset of breaking waves assumed as $5 \mathrm{~m} / \mathrm{s}, T_{w}$ is the significant wave period and assuming a fully developed sea-state can be calculated according to CERC (1984) as:

$$
T_{w}=8.13\left(\frac{\mathrm{U}_{\text {wind }}}{g}\right)
$$

$\Delta d$ is the oil droplet interval diameter, (m), equally spaced between $d_{\max }$ and $d_{\text {min }}$. After Reed et al. (1995) the maximum and minimum droplet size diameters are calculated as:

$d_{\text {max }}=3400 E^{-0.4}\left(v_{0}\right)^{0.34}$

$d_{\min }=500 E^{-0.4}\left(v_{o}\right)^{0.34}$

where $E$ is the wave energy dissipation rate per unit volume, $\left(\mathrm{J} / \mathrm{m}^{3} \mathrm{~s}\right)$ set as $5.0 \times 10^{3}$ after Delvigne and Sweeney (1988) as an intermediate value for breaking waves. The oil particle interval diameter was then constructed by adopting ten size classes between $d_{\min }$ and $d_{\max }$, equally spaced on diameter, as:

$\Delta d=\left(d_{\max }-d_{\min }\right) / 10.0$

The OILTRANS model randomly assigns a droplet diameter to each of the lagrangian particles based on the droplet distribution profile calculated from equations (33) and (34). The depth to which the dispersed oil droplets mix, $Z_{\text {mix }}$, is expressed as:

$$
Z_{\text {mix }}=\max \left(D_{v} / w_{d}, Z_{i}\right)
$$

where $D_{v}$ is the vertical diffusion coefficient $\left(\mathrm{m}^{2} / \mathrm{s}\right)$, equal to $0.0015 U_{\text {wind }}$ after Thorpe (1984), $w_{d}$ is the rise velocity $(\mathrm{m} / \mathrm{s})$ for droplet diameter $d$, and $Z_{i}$ is the intrusion depth $(\mathrm{m})$ of the breaking wave equal to $1.5 H_{b}$ after Delvigne and Sweeney (1988). The rise velocity, $w_{d}$, of the droplets is calculated based on the droplet Reynolds number with Stokes Law applied for small droplets and Reynolds Law applied for larger droplets, after Tkalich and Chan (2002). The total entrainment rate of oil into the water column, $Q_{\text {total }}\left(\mathrm{kg} / \mathrm{m}^{2} \mathrm{~s}\right)$, for all droplet size classes is:

$Q_{\text {total }}=\sum_{d=1}^{10} Q_{d}$

and the total mass entrained, $M_{\text {ent }}(\mathrm{kg})$, per time step is equal to:

$M_{\text {ent }}=Q_{\text {total }} A_{t} \Delta t$

The droplet sizes determine whether dispersed oil will re-surface and at what rate. Large droplet sizes will resurface faster than small droplets, which may remain permanently dispersed in the water column. Droplets which do not re-surface within the model time-step are assumed to be 
permanently dispersed within the water column. The current version of OILTRANS does not model

\subsubsection{Density}

The initial oil density is obtained from either the API gravity of the oil, or the density value and reference temperature, both contained within an oil database. Only oils with densities lower than water are modelled, as more dense oils will sink. The change in oil density over time is related to three different processes; changing water temperature, evaporation, and emulsification. The change in density due to changing temperature can be expressed as:

$\rho_{\text {oil }}=\rho_{\text {ref }}\left(1.0-C_{\text {Dens } T}\left(T-T_{\text {ref }}\right)\right)$

where $\rho_{\text {oil }}$ is density of oil $\left(\mathrm{g} / \mathrm{cm}^{3}\right)$, at temperature $T\left({ }^{\circ} \mathrm{K}\right)$ (assumed equal to the water temperature), $\rho_{\text {ref }}$ is the reference density of oil $\left(\mathrm{g} / \mathrm{cm}^{3}\right)$, at reference temperature $T_{\text {ref }}\left({ }^{\circ} \mathrm{K}\right), C_{\text {Dens } T}$ is an empirical constant equal to $8.0 \times 10^{-4}$ after Lehr et al. (2002). The change in density due to evaporation can be expressed as:

$\rho_{\text {oil }}=\rho_{\text {ref }}\left(1.0+C_{\text {DensE }} F_{\text {Evap }}\right)$

where $C_{\text {DensE }}$ is an empirical constant equal to $1.8 \times 10^{-2}$ after Lehr et al. (2002), $F_{\text {Evap }}$ is the fraction of oil evaporated from the slick. The change in density due to emulsification can be expressed as:

$\rho_{\text {oil }}=\left(\mathrm{Y} \rho_{w}\right)+\rho_{\text {ref }}(1.0-\mathrm{Y})$

Where $Y$ is the water content of the emulsion. Equations (38), (39) and (40) can be combined into one single equation to give the total change in density of the oil as (Buchanan and Hurford, 1988): $\rho_{\text {oil }}=\left(\mathrm{Y} \rho_{w}\right)+\rho_{\text {ref }}(1.0-\mathrm{Y})\left(1.0+C_{\text {DensE }} F_{\text {Evap }}\right)\left(1.0-C_{\text {DensT }}\left(T-T_{\text {ref }}\right)\right)$

\subsubsection{Viscosity}

The change in oil viscosity over time is related to three different processes; changing water temperature, evaporation, and emulsification. The change in density due to changing temperature can be expressed using Andrade's correlation as:

$v_{\text {oil }}=v_{\text {ref }} \exp \left(C_{\text {Temp }}\left(\frac{1}{T}-\frac{1}{T_{\text {ref }}}\right)\right)$

Where $v_{\text {oil }}$ is viscosity of oil (cSt) for given water temperature, $T\left({ }^{\circ} \mathrm{K}\right)$ (assumed equal to the water temperature), $v_{\text {ref }}$ is the reference viscosity of oil at reference temperature $T_{\text {ref }}\left({ }^{\circ} \mathrm{K}\right), C_{\text {Temp }}$ is an empirical constant equal to $5.0 \times 10^{3}$ after Lehr et al. (2002). The change in viscosity due to evaporation can be expressed as (Mackay et al., 1980): 
$v_{\text {oil }}=v_{\text {ref }} \exp \left(C_{\text {Evap }} \cdot F_{\text {Evap }}\right)$

where $F_{\text {Evap }}$ is the fraction of oil evaporated from the slick, $C_{E v a p}$ is an empirical constant equal to 10.0 after Reed (1989). The change in viscosity due to emulsification can be determined with reference to Table 2, above, after Fingas (2011) where:

$v_{\text {oil }}=v_{\text {refE }} V_{i s C_{\text {Emul }}}$

Where $v_{\text {refE }}$ is the oil viscosity at the onset of emulsification and is calculated from equations (42) and (43), Visc Emul $_{\text {is }}$ the interpolated viscosity multiplier from Table 2.

\section{Application to a spill incident in the Celtic Sea.}

The previous sections were focussed on the components of the OILTRANS modelling system and the general model formulations for oil transport and fate processes. In this section, the capability of the OILTRANS model is demonstrated through its application to an actual oil spill incident which occurred in the Celtic Sea on $14^{\text {th }}$ February 2009.

\subsection{Background}

The spill incident in the Celtic Sea involved the accidental release of oil during a ship-ship fuel transfer to the Russian naval vessel Admiral Kuznetsov. At the time of the incident it was estimated that 400-500 tonnes of a light crude oil was discharged (EMSA, 2010). The quantity of the spill was later revised down to 300 tonnes with the type of oil confirmed to be Mazut, which is a heavy, low quality crude oil (Irish Coastguard, pers. comm.). This incident represented the largest accidental spill in European waters in 2009 and the largest spill in waters around the British Isles since the Sea Empress ran aground off Milford Haven, Wales in 1996 (EMSA, 2010).

On Saturday the $14^{\text {th }}$ February 2009 at 10:54am, the European Maritime Safety Agency (EMSA) satellite surveillance programme CleanSeaNet detected an oil slick 100km south-east of Ireland's most southerly point, Mizen Hd., Co. Cork and notified the Irish and UK Coastguard agencies. Upon notification of the event, both the Irish and UK coastguard agencies tracked the evolution of the slick on an almost daily basis by aerial reconnaissance until $2^{\text {nd }}$ March by which time the surface slick was no longer visible.

The OILTRANS model was employed to simulate the transport and fate of the spilled oil for a ten day period from the $14^{\text {th }}$ to $23^{\text {rd }}$ February. The area of interest for this case study, within the authors' larger Northeast Atlantic operational model domain, is presented in Figure 3, and highlights the location of the Kuznetsov incident and the M3 databuoy which recorded wind speeds, directions and wave heights throughout the course of the incident. 


\subsection{Environmental Conditions}

Accurate environment information is essential for the reliable prediction of the transport and fate of oil pollution. The three most important sets of environmental information required are the spatially and temporally varying fields of wind, water current and waves. Accurate definition of these dynamic forcing conditions is fundamental to producing an accurate oil spill trajectory model. The wind fields defined to the OILTRANS model were obtained from the GFS re-analysis model predictions for the period in question. The winds at the location of the incident over the period were interpolated from the $0.5^{\circ} \mathrm{GFS}$ model predictions to the incident location and are shown in Figure 4(a). The wind blew predominantly in a north-northeasterly direction, though the wind rotated through all points of the compass throughout the ten day time period with wind speeds of $5.5 \mathrm{~m} / \mathrm{s}$ to $8.8 \mathrm{~m} / \mathrm{s}$ experienced for greater than $50 \%$ of the time.

The dynamic wave fields were defined to the OILTRANS model using the CERC (1984) deepwater wave formulations based on wind speeds predicted by the GFS re-analysis model for the period in question. The calculated significant wave heights at the incident location are presented in Figure 4(b). The surface currents at the incident location over the ten day period are shown in Figure 4(c), with surface current direction shown in Figure 4(d).

The surface current speeds defined to the OILTRANS model were obtained from the authors' operational Northeast Atlantic oceanographic model at hourly intervals. Maximum surface current speeds at the incident location were approximately $0.5 \mathrm{~m} / \mathrm{s}$ on the spring tide of the $14^{\text {th }}$ February, with highest neap tide surface currents approximately $0.15 \mathrm{~m} / \mathrm{s}$ occurring on the $19^{\text {th }}$ February.

\subsection{Model Simulation}

The OILTRANS model was used to simulate the trajectory and fate of the spilled oil over a ten day period, from the $14^{\text {th }}$ to $23^{\text {rd }}$ February 2009. The model was initialised at 00 :00hrs on $14^{\text {th }}$ February with the hydrodynamic fields from the authors Northeast Atlantic oceanographic model, wind fields from the pre-interpolated GFS re-analysis model and wave fields based on the CERC (1984) formulations. Thereafter, the above spatially and temporally varying met-ocean forcing fields were updated within the OILTRANS model at hourly intervals. It was assumed that the oil spill incident occurred instantaneously at $00: 00 \mathrm{hrs}$ on $14^{\text {th }}$ February with a discharge of 300 tonnes of Mazut crude oil. The exact time and duration of the spill incident was never established (Irish Coastguard, pers. comm.). The Mazut crude oil properties defined to the model are presented in Table 1. The trajectory of the oil spill particles were calculated at 5 minute intervals and the evolution of the oil weathering process were calculated at hourly intervals. The OILTRANS model simulation was executed until 00:00hrs on $24^{\text {th }}$ February. 


\section{Results and Discussion}

As is often the case in validating oil spill models, a lack of sufficient field data at the time of an oil spill event hampers the efforts to accurately calibrate model predictions. In the case of the incident in the Celtic Sea, daily reconnaissance over-flights of the oil slick were conducted thereby allowing the predicted oil slick trajectories from the OILTRANS model simulation be compared against the actual observations of the oil slick positions. Unfortunately, limited sampling of the actual spilled oil for analysis was undertaken. Only one sample from the $21^{\text {st }}$ February was available for comparison against OILTRANS model predictions. Therefore, for validation of the oil fates component of OILTRANS for the incident in question, recourse was made to comparing the predictions from the OILTRANS model against predictions from the publicly available ADIOS v2.0.1 oil weathering model (NOAA, 2012).

\subsection{Oil Slick Trajectory}

The OILTRANS oil slick trajectory predictions were compared against available aerial reconnaissance observations of the slick location for the period from the $14^{\text {th }}$ to $23^{\text {rd }}$ February 2009 and are presented in Figure 5. In general, the predictions from the OILTRANS model showed close agreement with both the observed slick locations and the overall trajectory of the oil slick throughout the ten days of model simulation.

From the beginning of the oil spill incident both the observed slick and the predicted slick travelled in a northeasterly direction until the $15^{\text {th }}$ February. The trajectory of the predicted slick was offset parallel to the observed slick by approximately $5 \mathrm{~km}$ during this time. From the $15^{\text {th }}$ to $18^{\text {th }}$ February the observed slick travelled in a east-northeasterly direction, with the predicted slick travelling in an easterly direction. The trajectory of the predicted slick intersected that of the observed slick on the $17^{\text {th }}$ February. During this period from $15^{\text {th }}$ to $18^{\text {th }}$ February the average difference between the observed slick and the predicted slick locations was approximately $4.5 \mathrm{~km}$. From the $18^{\text {th }}$ to $19^{\text {th }}$ February, both the observed and predicted slicks travelled in a northeasterly direction. During the period from the $19^{\text {th }}$ to $21^{\text {st }}$ February both slicks circulated in a clockwise manner with very close agreement between the positions of the observed and predicted slick locations. From the $21^{\text {st }}$ to $23^{\text {rd }}$ February, when the OILTRANS model simulation ended, both slicks travelled in an eastsoutheasterly direction. The difference between the location of the observed slick and predicted slick on the $22^{\text {nd }}$ February varied from $2.5-5.5 \mathrm{~km}$, whilst on the $23^{\text {rd }}$ February the difference between the locations of the observed slick and predicted slick varied from $4.5-11 \mathrm{~km}$ due to the 'comet' nature of the predicted slick shape. 


\subsection{Oil Slick Weathering}

The predictions from the OILTRANS oil weathering module were compared against predictions from the publicly available ADIOS v2.0.1 oil weathering model. The ADIOS model was executed with time varying wind fields from Figure 4(a) and time varying wave heights from Figure 4(b). The Mazut oil was defined as a custom oil to ADIOS using the specifications from Table 1. The maximum simulation time possible for the ADIOS model is 5 days. Comparison between the OILTRANS oil weathering module and the ADIOS oil model are presented in Figure 6 for a 5 day period.

Both the OILTRANS and ADIOS models predict that dispersion due to wave action is the primary mechanism through which the oil was removed from the water surface. OILTRANS predicted that $238 \mathrm{~m}^{3}$ (70.64\%) of the oil was removed by natural dispersion, whilst the ADIOS model predicted that $223 \mathrm{~m}^{3}$ (66.17\%) was removed by dispersion. The model predictions are broadly in keeping with reports from on-scene observers on the $21^{\text {st }}$ February who stated "...the slick is now quite dispersed and only a light sheen appears to remain a this time..." (Irish Coastguard, pers. comm.) The volume of oil predicted to have evaporated from the oil slick by the OILTRANS model was $34 \mathrm{~m}^{3}(10.18 \%)$ whilst the ADIOS model predicted $13 \mathrm{~m}^{3}$ (3.86\%) to have evaporated. The differences between the OILTRANS and ADIOS model predictions for volumes of oil evaporated and dispersed from the slick were seen in the volumes of oil remaining on the sea surface at the end of the model simulations as predicted by both models. The OILTRANS model predicted $64 \mathrm{~m}^{3}$ (19.18\%) of oil remained on the water surface, whilst ADIOS predicted that $101 \mathrm{~m}^{3}(29.97 \%)$ remained.

In addition to volumes of oil evaporated, dispersed and remaining on the water surface, OILTRANS also predicted the slick thickness, viscosity, density and water content throughout the course of the 10 day simulation from $14^{\text {th }}$ to $23^{\text {rd }}$ February as presented in Figure 7 . The OILTRANS model predicted the oil slick viscosity to increase gradually over the first 24 hours from the starting oil viscosity of 118cSt to190cSt. After the first 24 hours, during which evaporation of the lighter components of the oil had occurred, the viscosity of the oil increased significantly from 190cSt to 72,000 cSt signifying the emulsification of the oil due to the incorporation of water droplets. With the onset of emulsification, the OILTRANS model predicted a large increase in the water content of the oil, from a starting value of 0.06 to an emulsified value of 0.8 , signifying that the oil had formed a stable emulsion. Thereafter, the water content of the oil decreased slightly to a long term value of 0.77. OILTRANS also predicted an increase in density of the oil over the same time frame, from a starting value of $0.890 \mathrm{~g} / \mathrm{cm}^{3}$ to an eventual value of $1.001 \mathrm{~g} / \mathrm{cm}^{3}$. The OILTRANS model predicted the thickness of the initial oil slick to be approximately $1 \mathrm{~cm}$, with the slick thickness reducing over time to a final value of $0.132 \mathrm{~mm}(132 \mu \mathrm{m})$. 


\subsection{Model limitations and further development}

Accurate environment information is essential for the reliable prediction of the transport and fate of oil pollution. The three most important sets of environmental information required are the spatially and temporally varying fields of wind, water current and waves. OILTRANS can seamlessly incorporate operational model predictions for both wind fields (GFS) and water currents (ROMS) but currently has only limited capability to incorporate operational predictions of wave fields (SWAN). The limited capability relates to those instances of wave models which have a computational grid in common with the oceanographic ROMS model. Some effort is required to implement generic algorithms to interpolate native SWAN grids to the OILTRANS grid to overcome this limitation.

The ability of an oil spill model to accurately account for wave processes which disperse oil vertically into the water column during wave breaking is very important. In the application of the OILTRANS model to the oil spill incident in the Celtic Sea, the wave fields were calculated internally using the CERC (1984) deepwater wave equations for fully developed sea-states, equation (30) and equation (32). It was found that these equations under-predicted the significant wave height and significant wave period respectively when compared with actual field observations from the M3 databuoy. The M3 databuoy located just outside the case study area of interest, see Figure 3, recorded wind speeds, significant wave heights and periods on an hourly basis during the time of the Celtic Sea incident. Equation (30) was used to calculate significant wave heights at the M3 databuoy location using the M3 buoy recorded wind speeds. The superposition of the equation (30) computed significant wave heights with the M3 databuoy observed significant wave heights in Figure 8 shows a consistent under-prediction by equation (30) in almost all instances. Increased accuracy can be expected in the OILTRANS model's dispersion algorithms by incorporating operational wave model predictions into OILTRANS in place of the CERC (1984) formulations. This is highlighted in Figure 9 which presents the comparison of significant wave heights as predicted by the authors' recent SWAN model with the M3 databuoy observations of significant wave heights for a 30 day period in November 2011.

Another limitation of the OILTRANS modelling system which is linked to the vertical dispersion of oil droplets due to wave action, is the inability of the model to simulate the subsurface transport of dispersed oil droplets. Future development of the modelling system will see the incorporation of subsurface oil transport functionality.

Although the OILTRANS model's predictions for the various fate process of evaporation, emulsification and dispersion could not be compared against observations from the actual oil spill event due to insufficient data availability, the model's predictions were compared against one of the standard oil fate modelling applications, ADIOS. The OILTRANS model predicted volumes of oil 
evaporated, dispersed and remaining on the water which were close to those predicted by the

ADIOS model, though differences were evident. The differences in model predictions were due to the adoption of different formulations for the process of emulsification and different parameterisation of formulae for natural dispersion. Reed (1999) stated that two models purporting to contain the same algorithms may give quite different results from the same input data, and that the performance of one algorithm will be affected by performance of other algorithms in the model. Therefore, it was to be expected that the OILTRANS model would give different results to the ADIOS model owing to the adoption of different formulations and implementations. However, the broad similarity in results between the OILTRANS and ADIOS models provided confidence that the OILTRANS modelling system has accurately accounted for the dominant oil weathering processes.

\section{Conclusions}

A new oil spill transport and fate model, OILTRANS, which forms the basis of a newly developed operational oil spill forecasting system for Irish waters has been developed. The OILTRANS model consists of a set of algorithms based on the most widely used equations and empirical datasets to quantify the processes of advection, diffusion, mechanical spreading, evaporation, dispersion and emulsification. The model facilitates the implementation of differing algorithms for the processes of evaporation, emulsification and mechanical spreading of the oil slick. The model incorporates surface currents from an operational ROMS oceanographic model and wind fields from the operational GFS meteorological model. The OILTRANS model was applied to simulate the case of the accidental release of approximately 300 tonnes of Mazut heavy crude oil in the Celtic Sea on 14th February 2009. The aerial reconnaissance data acquired at the time of the oil spill incident was used to perform a validation test of the OILTRANS transport model. The trajectory and timing of the simulated oil slick's movement compared very well with the reconnaissance data. The main obstacle in presenting validation of the OILTRANS fate model algorithms was the difficulty in obtaining field data for the physical properties of the spilled oil during the course of the incident. Validation of the oil fates component of OILTRANS was made against the ADIOS oil model. The validation exercise verified that the model algorithms provided an encouraging level of accuracy when compared against results from the ADIOS oil model application. Further developments have been identified to improve the accuracy and functionality of the OILTRANS system.

\section{Acknowledgements}

The OILTRANS model was developed as part of ARCOPOL - The Atlantic Regions' Coastal Pollution Response Project (contract nr. 2008-1/061) funded by the Atlantic Area Trans-National 
Programme (Priority 2: Marine Environment and Renewable Energy) with support by the European

Regional Development Fund (ERDF). Data in relation to the Admiral Kuznetsov incident was kindly provided by the Irish Coastguard.

\section{List of Tables}

Table 1: Mazut oil properties

\section{List of Figures}

Figure 1: OILTRANS system schematic.

Figure 2: Elliptical spreading of a surface slick.

Figure 3: Operational Northeast Atlantic model domain showing the case study area of interest.

Figure 4: Time history of (a) wind speed, (b) wave height, (c) current speed and (d) current direction at incident location.

Figure 5: Comparison of OILTRANS model against observed slick positions from $14^{\text {th }}-23^{\text {rd }}$ February 2009.

Figure 6: Comparison of OILTRANS predictions against ADIOS v2.0.1 predictions.

Figure 7: OILTRANS model prediction of oil slick viscosity, thickness, water content and density. Figure 8: Comparison of equation (30) against M3 buoy recorded significant wave height, $\mathrm{H}_{\text {sig. }}$. Figure 9: Comparison of SWAN predictions against M3 buoy recorded significant wave height, $\mathrm{H}_{\text {sig. }}$

\section{References}

Aamo, O.M., Reed, M., Downing, K., 1995. Oil spill contingency and response (OSCAR) model system: sensitivity studies, 1995 Oil Spill Conference. American Petroleum Institute, pp. 429-438.

Al Rabeh, A.H., Cekirge, H.M., Gunay, N., 1989. A stochastic simulation model of oil spill fate and transport. Applied Mathematical Modelling 13, 323-329.

Al Rabeh, A.H., Lardner, R.W., Gunay, N., Hossain, M., 1995. OILPOL - an oil fate and transport model for the Arabian Gulf, Fourth Saudi Engineering Conference. King Abdul-Aziz University Press, Jeddah, pp. 415-427

Al Rabeh, A.H., Lardner, R.W., Gunay, N., 2000. Gulfspill version 2.0: a software package for oil spills in the Arabian Gulf. Environmental Modelling and Software 15, 425-442. 
Ambjorn, C., 2007. Seatrack web, forecasts of oil spills, a new version. Environmental Research, Engineering and Management 3, 60-66.

API, 1999. Fate of spilled oil in marine waters. API Publication No. 4691, American Petroleum Institute, p.43.

ASCE, 1996. State-of-the-art review of modelling transport and fate of oil spills. Journal of Hydraulic Engineering 122, 594-609.

Buchannan, I., Hurford, N., 1988. Methods for predicting the physical changes of oil spilled at sea. Oil and Chemical Pollution 4, 311-328.

Carracedo, P., Torres-Lopez, S., Barreiro, M., Montero, P., Balseiro, C.F., Penabad, E., Leitao, P.C., Perez-Munuzuri, V., 2006. Improvement of pollutant drift forecast system applied to the Prestige oil spills in Galicia coast (NW of Spain): development of an operational system. Marine Pollution Bulletin 53, 350-360.

CERC, 1984. Shore Protection Manual Volume I. Coastal Engineering Research Centre, Dept of the Army, Waterways Experiment Station, USACE, Vicksburg, MS, USA.

Cekirge, H.M., Kock, M., Long, C., Giammona, C.P., Binkley, K., Engelhardt, R., Jamail, R., 1995. State-of-the-art techniques in oil spill modelling, 1995 Oil Spill Conference. American Petroleum Institute, pp. 67-72.

Chao, X., Jothi Shankar, N., Wang, S.S.Y., 2003. Development and application of oil spill model for Singapore coastal waters. Journal of Hydraulic Engineering 129, 495-503.

CONCAWE, 1983. Characteristics of petroleum and it's behaviour at sea. CONCAWE's Oil Spill Cleanup Technology: Special Task Force No.8. Report No. 8/83. Den Haag, p.47

Daling, P.S., Aamo, O.M., Lewis, A., Strom-Kristiansen, T., 1997. SINTEF/IKU oil-weathering model: predicting oil's properties at sea, 1997 International Oil Spill Conference. American Petroleum Institute, pp 297-307. 
Delft, 2011. SWAN - Scientific and Technical documentation: version 40.85. Environmental Fluid Mechanics Section, Delft University of Technology.

Delvigne, G.A.L., Hulsen, L.J.M., 1994. Simplified laboratory measurements of oil dispersion coefficients - application in computations of natural oil dispersion, Seventeenth Arctic and Marine Oilspill Program Seminar, Environment Canada, Ontario, pp. 173 - 187.

Delvigne, G.A.L., Sweeney, C.E., 1988 Natural dispersion of oil. Oil and Chemical Pollution 4, 281-310.

Egbert, G.D., Erofeeva, S.Y., 2002. Efficient inverse modeling of barotropic ocean tides. J. Atmos. Oceanic Technol., 19, 183-204.

Elliott, A.J., 1991. EUROSPILL: Oceanographic processes and NW European shelf databases. Marine Pollution Bulletin 22, 548-553.

Elliott, A.J., Hurford, N., Penn, C.J., 1986. Shear diffusion and the spreading of oil slicks. Marine Pollution Bulletin 17, 308-313.

EMSA. 2010. Maritime Accident Review 2009. European Maritime Safety Agency, p.40

Fairall, C.W., Bradley, E.F., Rogers, D.P., Edson, J.B., Young, G.S., 1996. Bulk parameterization of air-sea fluxes for tropical ocean-global atmosphere: Coupled-Ocean Atmosphere Response Experiment. Journal of Geophysical Research 101, 3747-3764.

Fay, J.A., 1969. The spread of oil slicks on a calm sea, in: Hoult, D.P. (Ed.), Oil on the Sea. Plenum, New York, pp. 53-64.

Fay, J.A., 1971. Physical processes in the spread of oil on a water surface, Joint Conference on Prevention and Control of Oil Spills. American Petroleum Institute, pp. 117-125.

Fingas, M.F., 1999. The evaporation of oil spills: development and implementation of new prediction methodology. 1999 International Oil Spill Conference. American Petroleum Institute, pp 281-287 
Fingas, M.F., 2011. Models for water-in-oil emulsion formation, in: Fingas, M.F. (Ed.), Oil spill science and technology: prevention, response and cleanup. Gulf Professional Publishing , pp. 243273

Fingas, M., Fieldhouse, B., Mullin, J., 1999. Water-in-oil emulsions: results of formation studies and applicability to oil spill modelling. Spill Science and Technology Bulletin 5, 81-91.

Fingas, M.F., Fieldhouse, B., 2001.What causes the formation of water-in-oil-emulsions?, 2001 International Oil Spill Conference. American petroleum Institute, pp.109-114.

Fingas, M.F., Fieldhouse, B., 2003. Studies of the formation process of water-in-oil emulsions. Marine Pollution Bulletin 47, 369-396

Fingas, M.F., Fieldhouse, B., 2004. Formation of water-in-oil emulsions and application to oil spill modelling. Journal of Hazardous Materials 107, 37-50.

Fingas, M.F., Fieldhouse, B., 2006. A review of knowledge of water-in-oil emulsions. Proc. 29th AMOP Technical Seminar 1, 1-56

French-McCay, D.P., 2004. Oil spill impact modelling: development and validation. Environmental Toxicology and Chemistry 23, 2441-2456

Galt, J.A., 1994. Trajectory analysis for oil spills. Journal of Advanced Marine Technology Conference 11, 91-126.

GCWMB, 2003. The GFS Atmospheric Model. NCEP Office Note 442, Global Climate and Weather Modeling Branch, Environmental Modeling Center, Camp Springs MD, 2003.

Guo, W.J., Wang, Y.X., 2009. A numerical oil spill model based on a hybrid method. Marine Pollution Bulletin 58, 726-734.

Howlett, E., 1998. COZOIL users manual version 1.1: Improvement of model and linkage to graphical user interface. Applied Science Associates, RI, USA. 
IMDO, 2010. Irish Maritime Transport Economist, 7. Irish Maritime Development Office, Dublin, Ireland, p. 38.

IMDO, 2011. Irish Maritime Transport Economist, 8. Irish Maritime Development Office, Dublin, Ireland, p. 38.

Inan, A., Balas, L., 2010. Numerical modelling of oil spill. Water and Geoscience 1, 62-67

ITOPF, 2011. Oil tanker spill statistics 2011. International Tanker Owners Pollution Federation. London. p. 54.

Jeffrey, P.G., 1973. Large-scale experiments on the spreading of oil as sea and disappearance by natural factors, 1973 Oil Spill Conference. American Petroleum Institute, pp. 469-474.

Jones, R.K., 1997. A simplified pseudo component oil evaporation model, Twentieth Arctic Marine Oilspill Program Technical Seminar. Environment Canada, Ottawa, Ontario, pp. 43-61.

Lehr, W.J., Fraga, R.J., Belen, M.S., Cekirge, H.M., 1984. A new technique to estimate initial spill size using a modified Fay-type spreading formula. Marine Pollution Bulletin 15, 326-329.

Lehr, W., Jones, R., Evans, M., Simecek-Beatty, D., Overstreet, R., 2002. Revisions of the ADIOS oil spill model. Environmental Modelling and Software 17, 191-199.

Liungman, O., Mattsson, J., 2011. Scientific documentation of SeatrackWeb; physical processes, algorithms and references. Swedish Meteorlogical and Hydrological Institute, p32.

Mackay, D., Matsugu, R.S., 1973. Evaporation rates of liquid hydrocarbon spills on land and water. Canadian Journal of Chemical Engineering 51, pp 434-439

Mackay, D., Paterson, S., Trudel, K., 1980a. A mathematical model of oil spill behaviour. Report No. EE/7, Environment Canada, Ontario, p51.

Mackay, D., Buist, I., Mascarenhas, R., Patterson, S., 1980b. Oil Spill Processes and Models. Report No. EE/8, Environment Canada, Ontario. 
Mackay, D., McAuliffe, C.D., 1988. Fate of hydrocarbons discharged at sea. Oil and Chemical Pollution, 5, 1-20.

Nagheeby, M., Kolahdoozan, M., 2008. An Eulerian-lagrangian model for prediction of oil spill trajectory in seawater. COPEDEC VII, Dubai, UAE, Paper No: 212.

NOAA, 2002. Trajectory analysis handbook. Office of Response and Restoration, NOAA Ocean Service, Washington, USA, p. 42

NOAA, 2012. Automated Data Inquiry for Oil Spills v2.0.1. Emergency Response Division, Office of Response and Restoration, NOAA Ocean Service. http://response.restoration.noaa.gov/oil-andchemical-spills/oil-spills/response-tools/adios.html. last accessed: 10 ${ }^{\text {th }}$ April 2012.

North, E. W., Hood, R. R., Chao, S.-Y., and Sanford, L. P., 2006. Using a random displacement model to simulate turbulent particle motion in a baroclinic frontal zone: a new implementation scheme and model performance tests. Journal of Marine Systems 60, 365-380

North, E. W., Adams, E. E., Schlag, Z., Sherwood, C. R., He, R., Hyun, K. H., Socolofsky, S. A., 2011. Simulating oil droplet dispersal from the Deepwater Horizon spill with a Lagrangian approach, in: Liu, Y. et al.(Eds), Monitoring and Modeling the Deepwater Horizon Oil Spill: A Record-Breaking Enterprise, Geophys. Monogr. Ser., vol. 195, AGU, Washington, D. C., pp. 217226.

Payne, J.R., Kirstein, B.E., McNabb, G.D., 1983. Multivariate analysis of petroleum hydrocarbon weathering in the sub-arctic marine environment, 1983 Oil Spill Conference. American Petroleum Institute, pp. 423-434.

Pollani, A., Triantafyllou, G., Petihakis, G., Nittis, K., Dounas, C., Koutitas, C., 2001. The Poseidon operational tool for the prediction of floating pollutant transport. Marine Pollution Bulletin 43, 270278

Reed, M., 1989. The physical fates component of the natural resource damage assessment system. Oil \& Chemical Pollution 5, 99 -123 
Reed, M., Turner, C., Odulo, A., 1994. The role of wind and emulsification in modelling oil spill and surface drifter trajectories. Spill Science and Technology Bulletin 1, 143-157.

Reed, M., French, D., Rines, H., Rye, H., 1995. A three dimensional oil and chemical spill model for environmental impact assessment, 1995 Oil Spill Conference. American Petroleum Institute, pp. 61-66.

Reed, M., Johansen, Ø., Brandvik, P.J., Daling, P., Lewis, A., Fiocco, R., Mackay, D., Prentik, R., 1999. Oil spill model towards the close of the $20^{\text {th }}$ century; overview of the state of the art. Spill Science and Technology Bulletin 5, 3-16.

Sebastiao, P, Guedes Soares, C., 1995. Modelling the fate of oil spills at sea. Spill Science and Technology Bulletin, 2,122-131.

Shchepetkin, A. F., McWilliams, J. C., 2005. The regional oceanic modeling system (ROMS): a split-explicit, free-surface, topography-following-coordinate oceanic model. Ocean Modelling 9, 347-404.

Spaulding, M.L., 1988. A state of the art review of oil spill trajectory and fate modelling . Oil and Chemical Pollution 4, 69-55.

Spaulding, M.L., Howlett, E., Anderson, E., Jayko, K., 1992. OILMAP: A global approach to spill modelling, Fifteenth Annual Arctic and Marine Oil Spill Program. Environment Canada, Ottawa, Ontario, pp. 15-21.

Stiver, W., Mackay, D., 1984. Evaporation rate of spills of hydrocarbons and petroleum mixtures. Environmental Science and Technology 18, 834-840.

Thorpe, S.A., 1984. On the determination of $\mathrm{K}_{\mathrm{v}}$ in the near surface ocean from acoustic measurements of bubbles. Journal of Physical Oceanography 14, 855 - 863

Tkalich, P., Chan, E.S., 2002. Vertical mixing of oil droplets by breaking waves. Marine Pollution Bulletin 44, 1219-1229. 
Tkalich, P., Xiaobo, C., 2001. Accurate simulation of oil slicks, 2001 International Oil Spill Conference. American Petroleum Institute, pp. 1133-1137.

Wang, J.H., Shen, Y.M., 2010. Development of an integrated model system to simulate transport and fate of oil spills in seas. Science China Technological Series 53, 2423-2434. 


$\begin{array}{lll}\text { Parameter } & \text { value } & \text { units } \\ \text { Density at } 15^{\circ} \mathrm{C} & 0.89 & \mathrm{~g} / \mathrm{ml} \\ \text { Kinematic viscosity at } 80{ }^{\circ} \mathrm{C} & 118 & \mathrm{CSt} \\ \text { Asphaltenes } & 3.6 & { }^{\%} \\ \text { Distillation } & & \\ 5 \% \text { recovered } & 259 & { }^{\circ} \mathrm{C} \\ \text { 10\% recovered } & 310 & { }^{\circ} \mathrm{C} \\ \text { 20\% recovered } & 358 & { }^{\circ} \mathrm{C} \\ \text { 30\% recovered } & 445 & { }^{\circ} \mathrm{C} \\ 40 \% \text { recovered } & 502 & { }^{\circ} \mathrm{C} \\ 50 \% \text { recovered } & 534 & { }^{\circ} \mathrm{C} \\ 60 \% \text { recovered } & 538 & { }^{\circ} \mathrm{C} \\ 75 \% \text { recovered } & 545 & { }^{\circ} \mathrm{C} \\ 78 \% \text { recovered } & 550 & { }^{\circ} \mathrm{C}\end{array}$



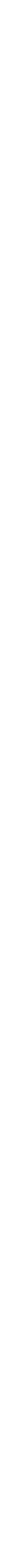


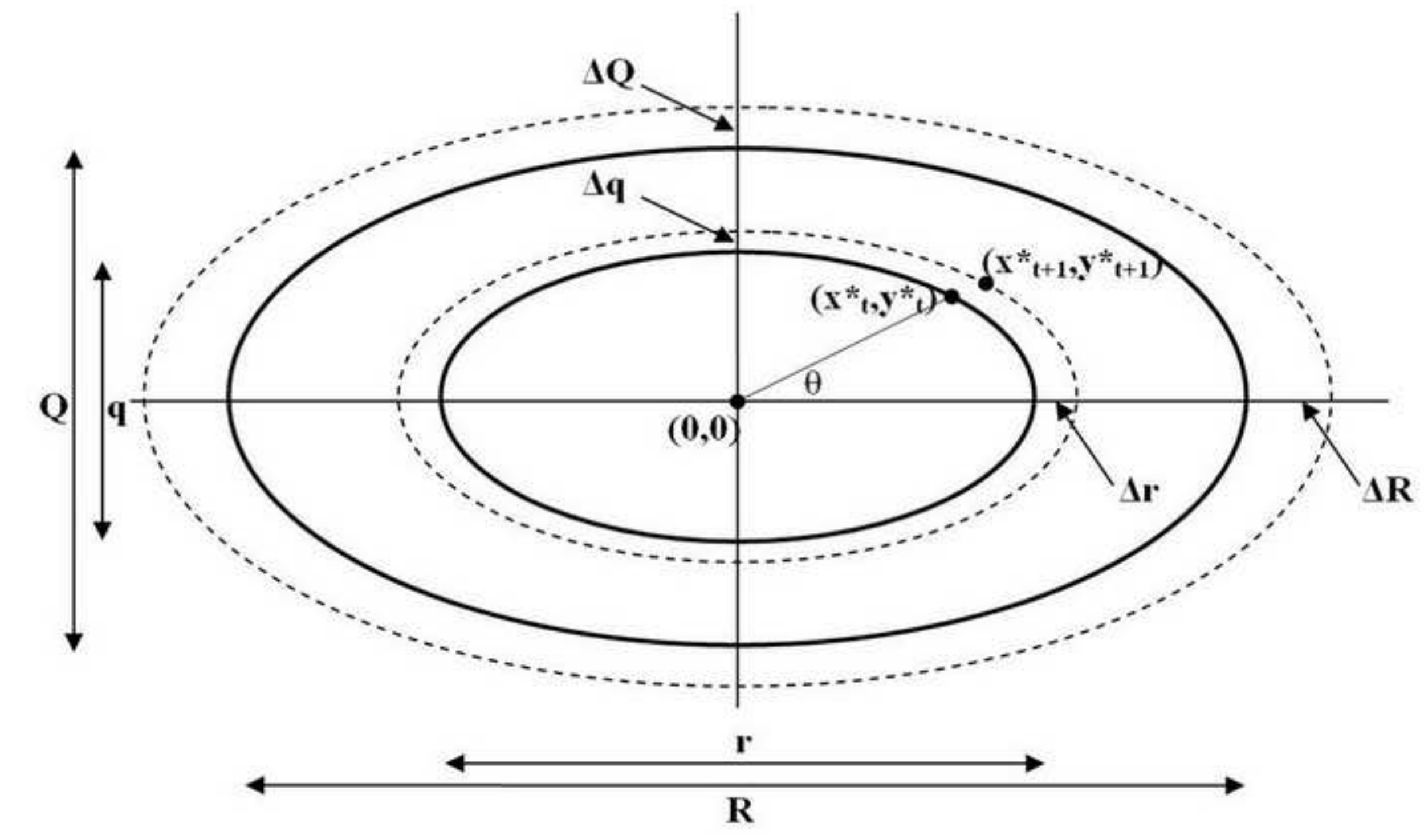

Click here to download high resol 


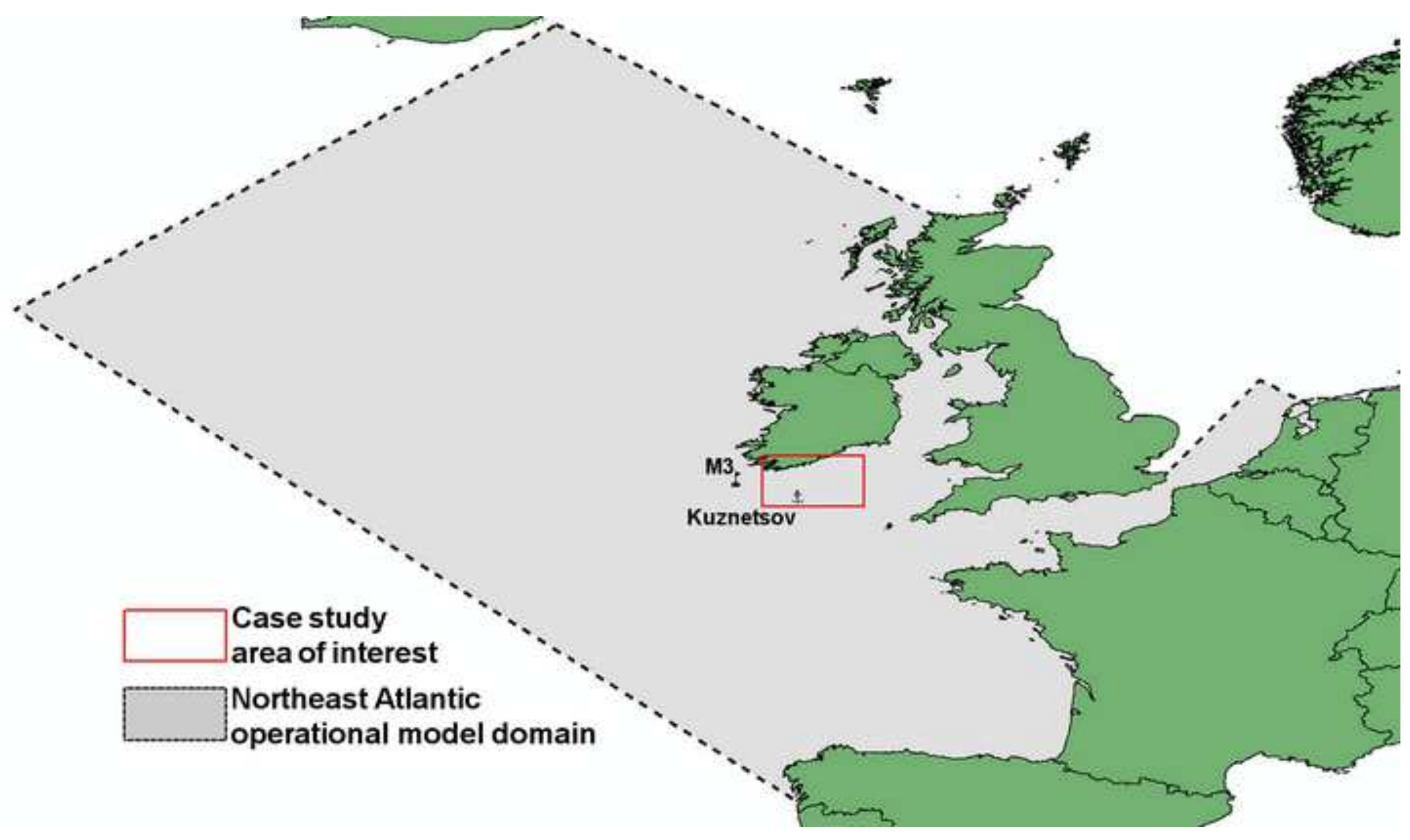


Click here to download high resolution image
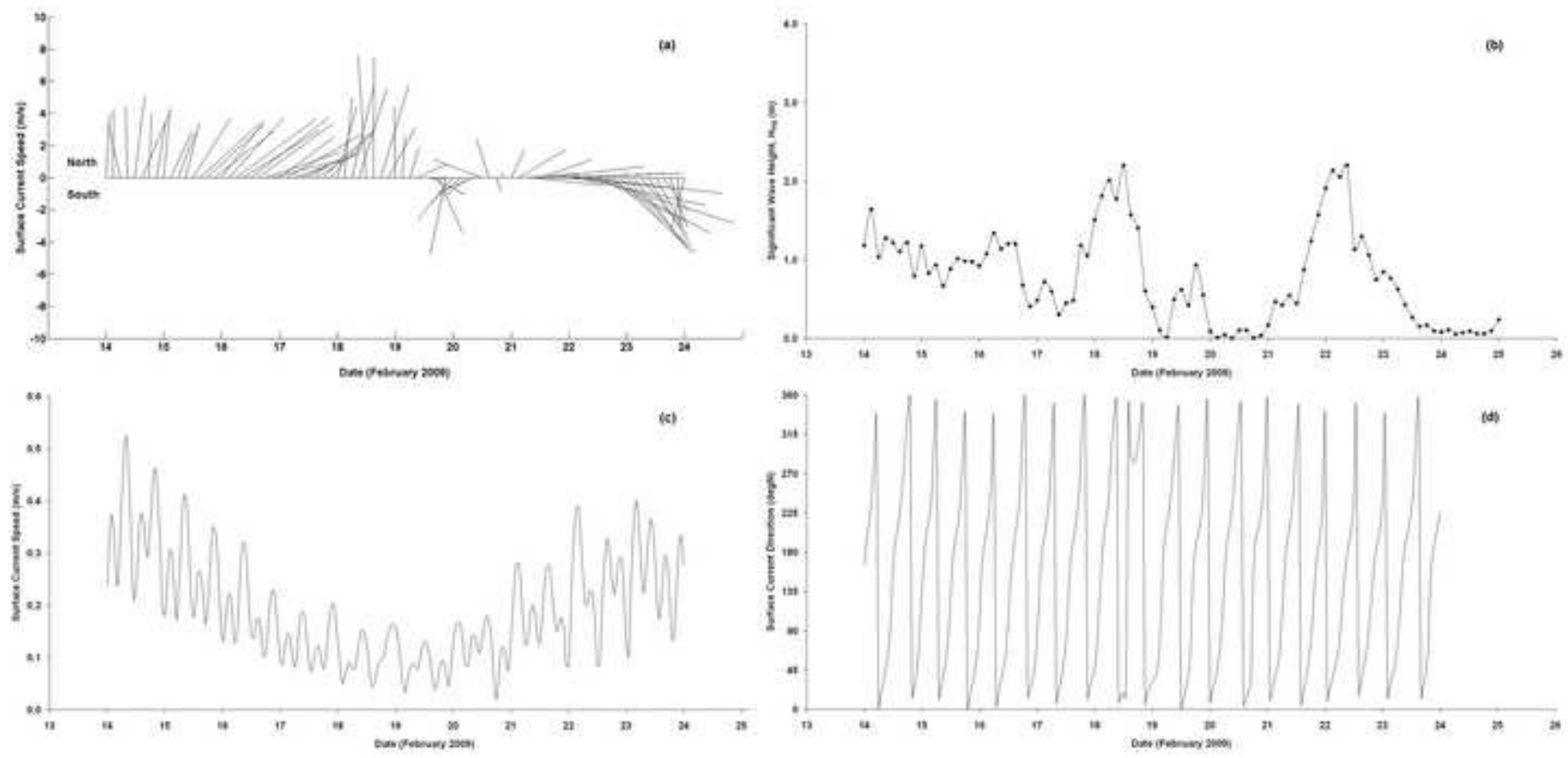
Click here to download high resolution image

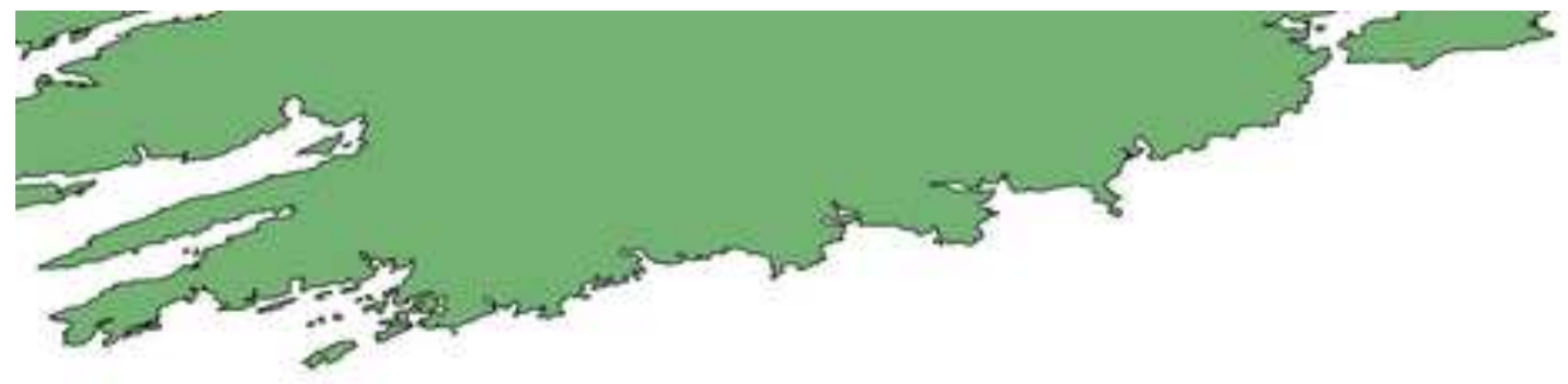

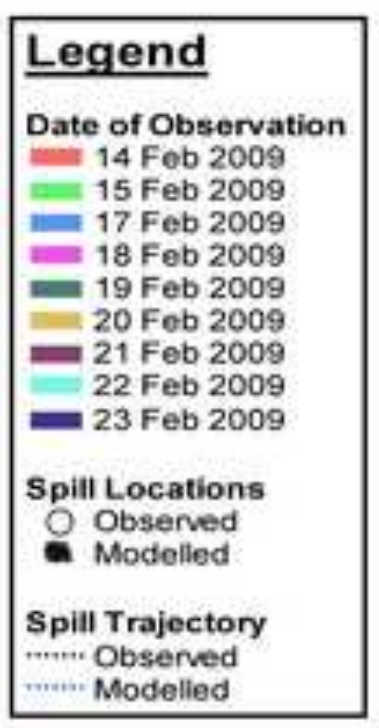

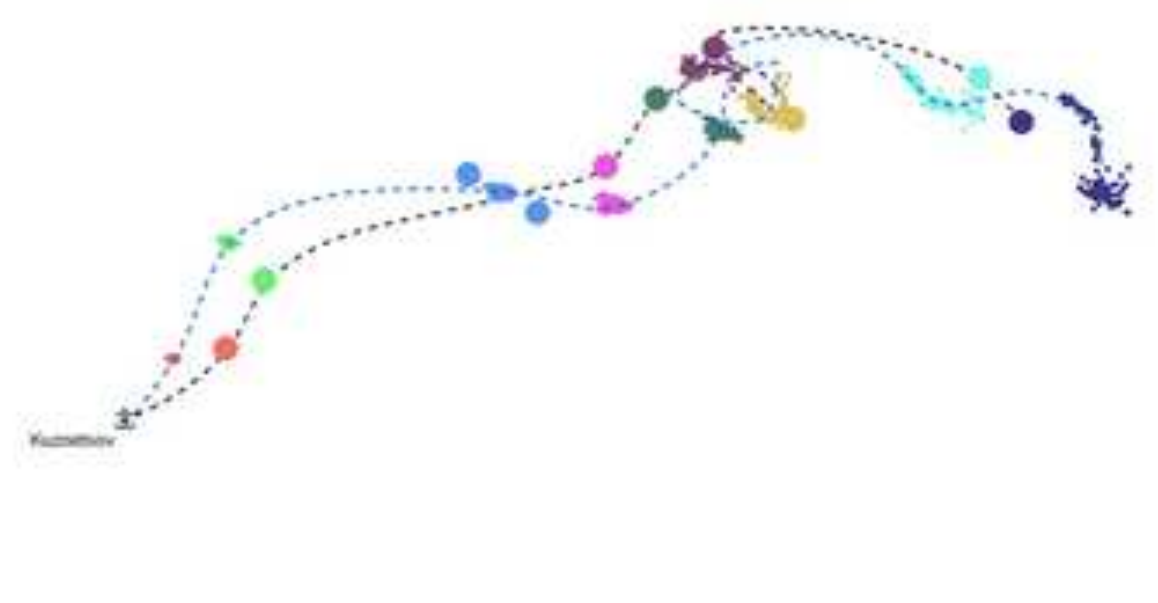


Click here to download high resolution image

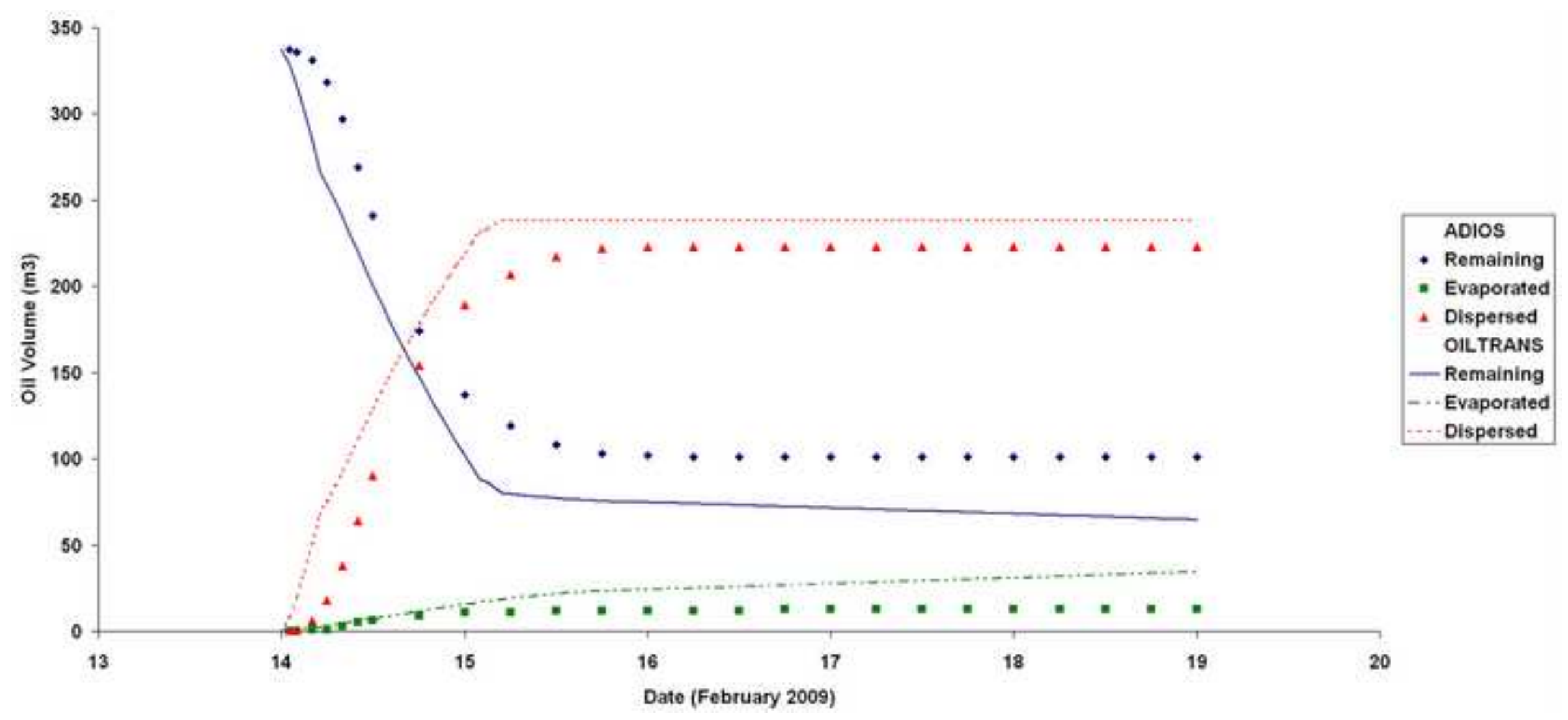


Click here to download high resolution image

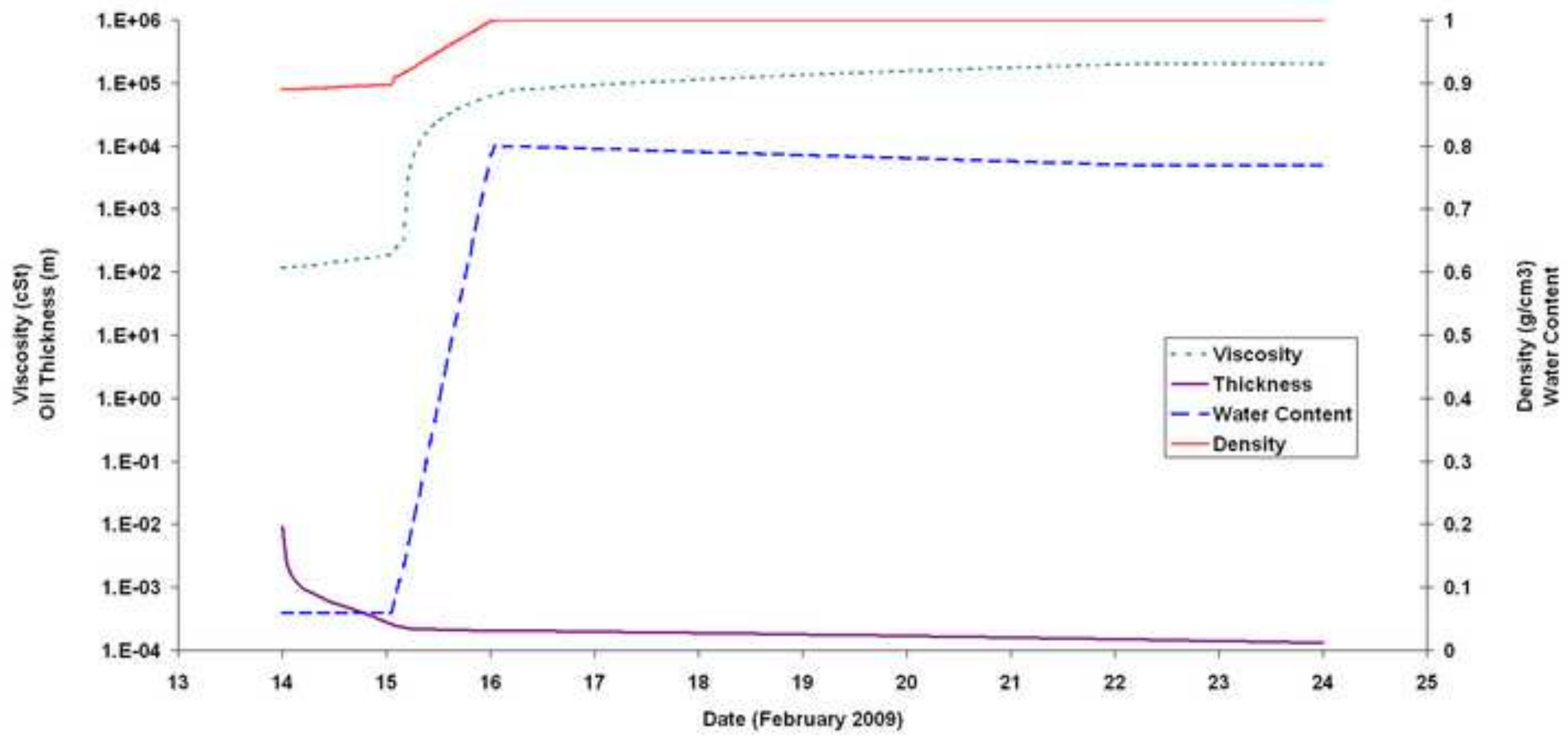




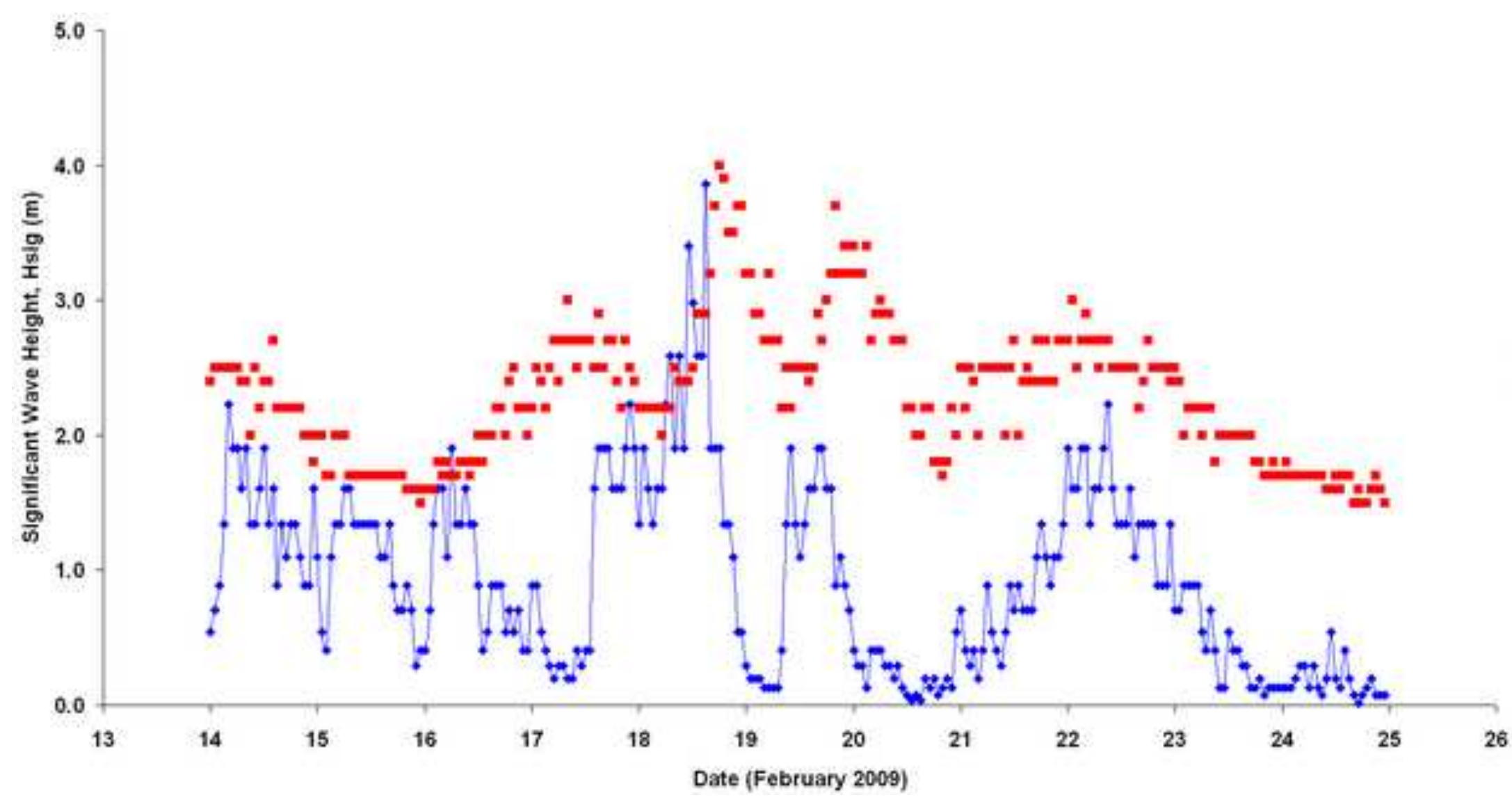




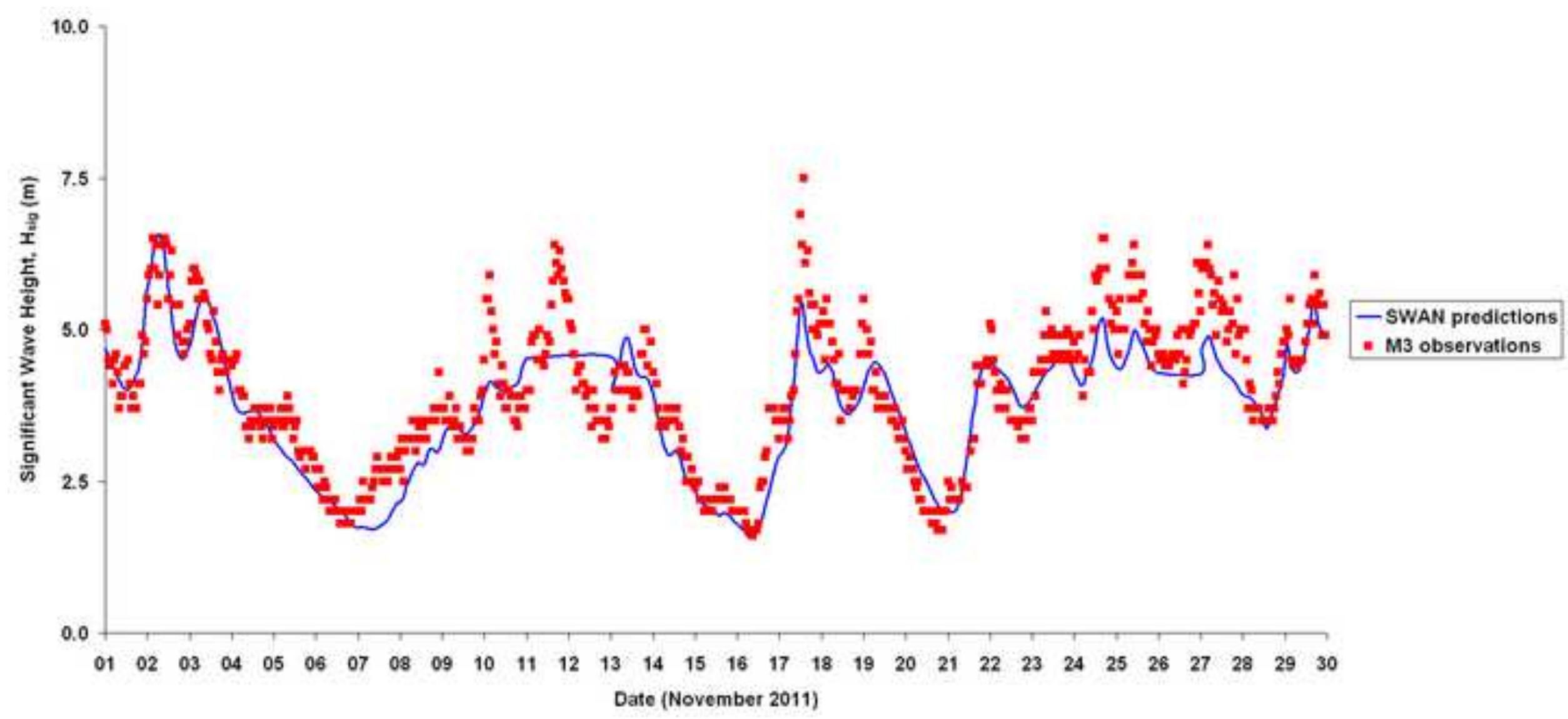

